\title{
Aerodynamic properties of Makhobeli, triticale and wheat seeds
}

\author{
Feizollah Shahbazi*, Saman Valizadeh, and Ali Dowlatshah \\ Department of Biosystems Engineering, Lorestan University, Khorramabad, Iran
}

Received April 23, 2012; accepted January 2, 2014

\begin{abstract}
A b s tract. The objective of this study was the evaluation of the aerodynamic properties of Makhobeli, triticale and wheat seeds as a function of moisture content from 7 to $27 \%$ (w.b). The results showed that the terminal velocity of triticale and wheat seeds increased linearly from 5.37 to 6.42 and from 6.31 to $8.02 \mathrm{~m} \mathrm{~s}^{-1}$, respectively, as the moisture content increased from 7 to $27 \%$. Over this same moisture content range, the terminal velocity of Makhobeli seeds varied following a polynomial relationship from 4.52 to $5.07 \mathrm{~m} \mathrm{~s}^{-1}$. Makhobeli seeds had terminal velocities with a mean value of $4.73 \mathrm{~m} \mathrm{~s}^{-1}$, at different moisture contents, compared to the mean values of 5.89 and $7.13 \mathrm{~m} \mathrm{~s}^{-1}$ for triticale and wheat seeds, respectively. The mean value of drag coefficient was 1.12 for Makhobeli compared to the values of 0.92 and 0.85 for triticale and wheat, respectively. The analysis of variance showed that there were significant differences between the terminal velocity (at $1 \%$ probability level) and drag coefficient (at 5\% probability level) of Makhobeli with triticale and wheat seeds, which suggests that aerodynamic separation of Makhobeli from triticale and wheat is possible.

K e y w o r d s: separation, post harvest operation, Makhobeli, weed control, triticale, wheat
\end{abstract}

\section{INTRODUCTION}

Makhobeli (Cephalaria syriaca L.) is an annual plant that is a weed in wheat fields in some parts of the Middle East because of its stature, penology and retention of seeds and the resemblance of the seed to wheat (Karaoglu, 2006). Although it is very bitter, it is not toxic (Musselman, 2000). This plant is generally encouraged to grow in triticale and wheat fields in Iran, so that its edible seed will be mixed with triticale and wheat grains, and when it is harvested and ground together with triticale and wheat, it gives a slight blue shade and a bitter taste to the bread. However, the seed of Makhobeli is similar to triticale and wheat grains in size and shape, so the separation of Makhobeli seeds from triticale and wheat is very difficult. To overcome this

*Corresponding author e-mail: shahbazi.f@lu.ac.ir problem, some type of equipment is needed to be designed that will perform this separation. However, in order to do this, thorough knowledge on the aerodynamic properties of triticale and wheat as well as Makhobeli seeds may lead to a point at which some type of pneumatic device can be envisaged.

The behaviour of particles in an air stream during pneumatic conveying and separation greatly depends on their aerodynamic properties. The aerodynamic forces which exist during relative motion between the air and the materials act differently on different particles. Separation of a mixture of particles in a vertical air stream is only possible when the aerodynamic characteristics of the particles are so different that the light particles are entrained in the air stream and the heavy particles fall through it. Knowledge of aerodynamic properties is therefore essential in the proper design of separating and cleaning equipments. When an air stream is used for separating a product such as wheat seed from its associated foreign materials, such as straw, chaff and weed seeds, knowledge of aerodynamic characteristics of all the particles involved is necessary. This helps to define the range of air velocities for effective separation of the grain from foreign materials. For this reason, the terminal velocity has been used as an important aerodynamic characteristic of materials in such applications as pneumatic conveying and their separation from foreign materials (Mohsenin, 1978).

Several investigators determined the aerodynamic properties of various seeds such as cheat seed by Hauhouot et al. (2000), different varieties of rice, corn, wheat and barley by Matouk et al. (2005), pine nuts by Ozguven and Vursavus (2005), wheat kernel by Khoshtaghaza and Mehdizadeh (2006), makhana by Jha and Kachru (2007), Turgenia latifolia seeds and wheat kernels by Nalbandi et al. (2010) and wild mustard by Shahbazi (2013). 
The objective of this investigation was to measure and compare the aerodynamic properties of Makhobeli, triticale and wheat seeds to provide the data and to facilitate the design and adjustment of machines that perform separation of Makhobeli from triticale and wheat based on aerodynamic properties.

\section{MATERIALS AND METHODS}

The Makhobeli, triticale and wheat seeds used for the present study were obtained from a field in the Lorestan University that were cultivated in the same conditions during the 2011 cultivation season. After attaining optimum maturity, samples of seeds were harvested by hand and cleaned in an air screen cleaner. The initial moisture content of Makhobeli, triticale and wheat seeds was 6.51, 6.84 and 7\% (w.b.), respectively, determined with ASAE S352.2 (ASAE, 1988). Higher moisture content samples were prepared by adding calculated amounts of distilled water, then sealing in polyethylene bags and storing at $5^{\circ} \mathrm{C}$ for 15 days. Samples were warmed to room temperature before each test and moisture content was verified. Sample mass was recorded with a digital electronic balance having an accuracy of $0.001 \mathrm{~g}$.

The major dimensions of the seeds ( $L$ and $W$ ) were measured using a digital caliper with an accuracy of $\pm 0.01 \mathrm{~mm}$ (Gupta et al., 2007). The true density of the seeds was measured using the toluene displacement method (Chakraverty and Poul, 2001; Unal et al., 2013; Zare et al., 2013).

To determine the terminal velocity value of seeds, a vertical wind tunnel was designed, constructed and used. A centrifugal fan powered by one HP motor was used in the inlet of the wind tunnel to supply air flow. The air flow rate of the fan was controlled at inlet by adjusted by changing the velocity of the electric motor through an inverter set and a diaphragm. The final section of the wind tunnel consisted of a Plexiglas region where the terminal velocity of seed was measured. To determine the terminal velocity, each seed was placed in the centre of the cross section of the wind tunnel on the screen. The air flow was then increased until the seed flotation point. At this moment, when the rotational movement of the seed was the lowest, the air velocity was measured using a hot-wire anemometer with an accuracy of $0.1 \mathrm{~m} \mathrm{~s}^{-1}$. The terminal velocity of each seed was measured two times. For each condition the terminal velocity was calculated as the average of the velocity values obtained at the centre of the test section and at the four equidistantly distributed points on two orthogonal axes located at the test section. To determine the terminal velocity at each moisture content level, ten seeds were selected and used as ten replications in the statistical analysis. The values of air density was taken as $1.206 \mathrm{~kg} \mathrm{~m}^{-3}$ at room temperature of $20^{\circ} \mathrm{C}$.

In free fall, the object will attain a constant terminal velocity $\left(V_{t}\right)$ at which the net gravitational accelerating force $\left(F_{g}\right)$ equals the resisting upward drag force $\left(F_{r}\right)$ under the condition where terminal velocity has been achieved the air velocity which equal to the terminal velocity $\left(V_{t}\right)$. Substituting for $F_{g}$ and $F_{r}$, the expression for terminal velocity will be as follows (Mohsenin, 1978):

$$
V_{t}=\sqrt{\frac{2 m \mathrm{~g}\left(\rho_{p}-\rho_{f}\right)}{\rho_{p} \rho_{f} A_{p} C_{d}}} .
$$

The drag coefficient can be derived as follows:

$$
\begin{gathered}
C_{d}=\frac{2 m \mathrm{~g}\left(\rho_{p}-\rho_{f}\right)}{\rho_{p} \rho_{f} A_{p} V_{t}^{2}}, \\
A_{p}=\frac{\pi}{4} L W,
\end{gathered}
$$

where: $A_{p}$ is projected area of the particle $\left(\mathrm{m}^{2}\right), C_{d}$ is drag coefficient (dimensionless), $\mathrm{g}$ is acceleration due to gravity $\left(9.81 \mathrm{~m} \mathrm{~s}^{-2}\right), L$ is seed length $(\mathrm{m}), m$ is mass of seeds $(\mathrm{kg})$, $V_{t}$ is terminal velocity $\left(\mathrm{m} \mathrm{s}^{-1}\right), W$ is seed width $(\mathrm{m}), \rho_{f}$ is density of air $\left(1.206 \mathrm{~kg} \mathrm{~m}^{-3}\right), \rho_{p}$ is density of seeds $\left(\mathrm{kg} \mathrm{m}^{-3}\right)$.

In this study, the effects of seed crop (Makhobeli, triticale and wheat) and moisture content (7, 12, 17, 22, and $27 \%$ w.b.) on the terminal velocity and drag coefficient of seeds were analyzed. Tests were conducted over a range of moisture contents from 7 to $27 \%$ which spans the moisture range from harvest to the milling operation. The factorial experiment was conducted as a randomized design with three replicates. For each test, 10 seeds were selected randomly from each sample and tested by using the airflow device. Mean comparison of factors was carried out at $5 \%$ probability level. The terminal velocity and drag coefficient and the moisture content data of different seed crops were fitted to linear, power, exponential and polynomial models. The models were evaluated according to the statistical criterion $\mathrm{R}^{2}$ for verifying the adequacy of fit. The best model with the highest $\mathrm{R}^{2}$ was selected to predict the terminal velocity and drag coefficient of seeds as a function of moisture content. Data were analyzed by SPSS and MATLAB software.

\section{RESULTS AND DISCUSSION}

The average values of dimensions, projected area and true density of crop seeds at different moisture contents are presented in Table 1. The analysis of variance showed that there was a significant difference between the terminal velocity of Makhobeli, triticale and wheat seeds at $1 \%$ probability level $(\mathrm{p}<0.01)$. In addition, the effect of seed moisture content on this property was significant at $1 \%$ probability level (Table 2). Meanwhile, the interaction effects of seed crop $\times$ moisture content was not significant for the terminal velocity of seeds $(\mathrm{p}>0.05)$.

Figure 1 shows the variation of the terminal velocity with moisture content for Makhobeli, triticale and wheat seeds. The terminal velocity of all crop seeds increased with 
T a b l e 1. Average values of dimensions, projected area, and true density of seeds at different moisture contents

\begin{tabular}{ccccc}
\hline $\begin{array}{c}\text { Moisture content } \\
(\%)\end{array}$ & $\begin{array}{c}\text { Length } \\
(\mathrm{mm})\end{array}$ & $\begin{array}{c}\text { Width } \\
(\mathrm{mm})\end{array}$ & $\begin{array}{c}\text { Projected area } \\
\left(\mathrm{mm}^{2}\right)\end{array}$ & $\begin{array}{c}\text { True density } \\
(\mathrm{kg} \mathrm{m})^{-3}\end{array}$ \\
\hline 7 & $3.44(0.26)$ & Makhobeli & $3.32(0.49)$ & $883.12(2.23)$ \\
12 & $3.69(0.48)$ & $1.23(0.12)$ & $4.78(1.59)$ & $898.21(3.14)$ \\
17 & $4.29(0.56)$ & $1.70(0.63)$ & $5.73(2.08)$ & $1012.18(8.98)$ \\
22 & $4.35(0.35)$ & $2.22(0.48)$ & $7.59(0.94)$ & $1039.07(11.24)$ \\
27 & $4.44(0.51)$ & $2.42(0.46)$ & $8.42(0.59)$ & $1103.81(9.36)$ \\
7 & & triticale & $17.89(1.69)$ & $1121.02(10.24)$ \\
12 & $8.35(0.56)$ & $2.73(0.22)$ & $19.67(0.97)$ & $1139.03(11.78)$ \\
17 & $8.72(0.44)$ & $2.87(0.19)$ & $20.69(0.95)$ & $1179.83(8.87)$ \\
22 & $8.73(0.28)$ & $3.02(0.12)$ & $24.88(1.14)$ & $1201.28(9.68)$ \\
27 & $9.16(0.48)$ & $3.47(0.34)$ & $27.97(1.12)$ & $1270.12(7.17)$ \\
7 & $9.17(0.26)$ & $3.88(0.53)$ & & $1289.59(6.58)$ \\
12 & & wheat & $16.78(0.61)$ & $1310.02(10.23)$ \\
22 & $6.27(0.14)$ & $3.41(0.56)$ & $17.26(1.80)$ & $1321.09(12.35)$ \\
17 & $6.33(0.15)$ & $3.47(0.31)$ & $17.30(0.73)$ & $1338.91(15.78)$ \\
\hline
\end{tabular}

Standard deviation in parentheses.

T a b l e 2. Analysis of variance (mean square) for the terminal velocity and drag coefficient

\begin{tabular}{lccc}
\hline \multirow{2}{*}{$\begin{array}{l}\text { Source of } \\
\text { variation }\end{array}$} & $\begin{array}{c}\text { Degree } \\
\text { of } \\
\text { freedom }\end{array}$ & $\begin{array}{c}\text { Terminal } \\
\text { velocity }\end{array}$ & $\begin{array}{c}\text { Drag } \\
\text { coefficient }\end{array}$ \\
\cline { 3 - 4 } Seed crop & 2 & $21.645^{* *}$ & $0.302^{*}$ \\
$\begin{array}{l}\text { Moisture content } \\
\text { Seed crop } \times\end{array}$ & 4 & $1.776^{* *}$ & $0.501^{* *}$ \\
moisture content & 8 & $0.181 \mathrm{~ns}$ & $0.046 \mathrm{~ns}$ \\
Error & 30 & 0.065 & 0.040 \\
\hline
\end{tabular}

Significant at: $* 0.05, * * 0.01$ probability levels, ns - not significant.

increasing moisture content (Fig. 1). The results of the Duncan multiple range tests for comparing the means of the terminal velocity of Makhobeli, triticale and wheat seeds are shown in Table 3. As the moisture content of seeds increased from 7 to $27 \%$, the measured terminal velocities for Makhobeli seeds ranged from 4.52 to $5.07 \mathrm{~m} \mathrm{~s}^{-1}$ (Fig. 1), with a mean value of $4.73 \mathrm{~m} \mathrm{~s}^{-1}$ and a standard deviation of 0.22 (Table 3 ). Measured terminal velocity for triticale seeds had a mean of $5.89 \mathrm{~m} \mathrm{~s}^{-1}$ and a standard deviation of 0.51 (Table 3 ) and the range was from 5.37 to $6.42 \mathrm{~m} \mathrm{~s}^{-1}$. Measured terminal velo-

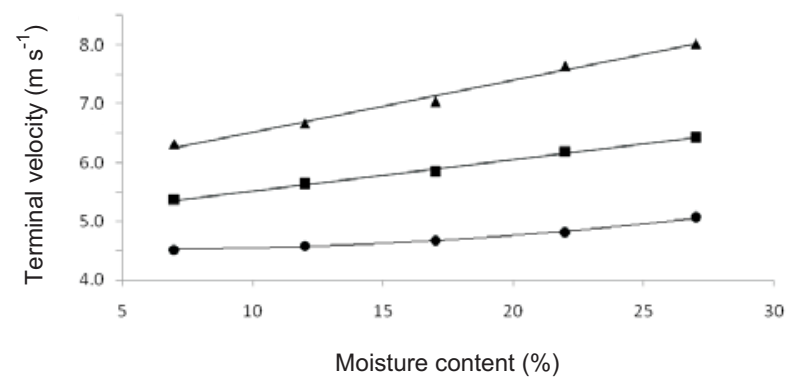

Fig. 1. Terminal velocity variation $v s$. seed moisture content: - Makhobeli, $\mathbf{\square}$ triticale, $\boldsymbol{\Delta}$ wheat.

cities for wheat seeds ranged from 6.31 to $8.02 \mathrm{~m} \mathrm{~s}^{-1}$, with a mean value of $7.13 \mathrm{~m} \mathrm{~s}^{-1}$ and a standard deviation of 0.66 (Table 3). These results are in agreement with published literature data for some seeds. Gupta et al. (2007) showed that in the moisture range of 6 to $14 \%$ d.b., the terminal velocity of NSFH-36, PSF-118 and Hybrid SH-3322 variety of sunflower seed increased from 2.93 to $3.28,2.54$ to 3.04 , and 2.98 to $3.53 \mathrm{~m} \mathrm{~s}^{-1}$, respectively. Zewdu (2007) measured the terminal velocity of Tef grains. Author reported that it increased linearly from 3.08 to $3.96 \mathrm{~m} \mathrm{~s}^{-1}$ with increasing moisture content from 6.5 to $30.1 \%$ w.b. Hauhouot et al. (2000) showed that the mean value of terminal velocity of 
T a b I e 3. Results of Duncan multiple range tests for comparing the means of the aerodynamic properties of Makhobeli, triticale and wheat seeds

\begin{tabular}{lcc}
\hline \multirow{2}{*}{$\begin{array}{c}\text { Independent } \\
\text { variable } \\
\text { (seed crop) }\end{array}$} & \multicolumn{2}{c}{ Dependent variable (aerodynamic properties) } \\
\cline { 2 - 3 } & Terminal velocity $\left(\mathrm{m} \mathrm{s}^{-1}\right)$ & Drag coefficient \\
\hline Makhobeli & $4.73(0.22) \mathrm{c}$ & $1.12(0.43) \mathrm{a}$ \\
Triticale & $5.89(0.51) \mathrm{a}$ & $0.92(0.21) \mathrm{b}$ \\
Wheat & $7.13(0.66) \mathrm{b}$ & $0.85(0.44) \mathrm{c}$ \\
\hline
\end{tabular}

Values in the vertical column with the same letters are not significant at 5\% level. Explanations as in Table 1.

wheat seeds was $7.84 \mathrm{~m} \mathrm{~s}^{-1}$. The terminal velocity of millet grain varied from 2.75 to $4.63 \mathrm{~m} \mathrm{~s}^{-1}$ for an increase in moisture content from 5 to $22.5 \%$ d.b. (Baryeh, 2002). Matouk et al. (2008) reported that the terminal velocity of sunflower, soybean and canola seeds increased from 5.34 to 5.91 , from 10.16 to 10.38 and from 5.10 to $5.32 \mathrm{~m} \mathrm{~s}^{-1}$ with increasing seed moisture content from 7.35 to $23.7,9.52$ to $24.64 \%$ and 7.11 to $25.72 \%$ w.b., respectively. Similar results were reported for cotton seeds (Tabak and Wolf, 1998), coffee cherries and beans (Afonso et al., 2007), African yam bean (Irtwange and Ugbeka, 2003). The increase in terminal velocity with an increase in moisture content may be attributed to the increase in mass of an individual seed per unit frontal area presented to the air stream. The other reason is probably that the drag force is affected by the moisture content of particle.

From the data in Fig. 1 it can be seen hat the ranges of terminal velocity for Makhobeli, triticale and wheat seeds do not overlap in all moisture contents (Fig. 1). In addition, the differences between the mean values of the terminal velocity for Makhobeli, triticale and wheat seeds are significant $(\mathrm{p}=0.05)$ (Table 3). There are 1.16 and $2.40 \mathrm{~m} \mathrm{~s}^{-1}$ differences between the terminal velocity of Makhobeli seeds with triticale and wheat seeds, respectively. Consequently, aerodynamic separation of Makhobeli from triticale and wheat is theoretically possible.

The terminal velocity data for Makhobeli, triticale and wheat seeds in Fig. 1 were fitted as a function of moisture content to four mathematical models. These models were evaluated for verifying the adequacy of fit using the $\mathrm{R}^{2}$ value. By comparing the average values of $\mathrm{R}^{2}$, it was obvious that the polynomial model for Makhobeli and the linear model for triticale and wheat had the highest $\mathrm{R}^{2}$ values. Accordingly, the polynomial model was selected as a suitable model to predict the terminal velocity of Makhobeli seeds as a function of moisture content. In addition, the linear models were selected for triticale and wheat seeds. Razavi et al. (2007) developed a linear equation between the terminal velocity of pistachio nut and kernel as a function of moisture content. Zewdu (2007) reported that the terminal velocity of Tef grain was linearly related to moisture content. However, Afonso et al. (2007) reported a non-linear equation for the terminal velocity of coffee cherry and bean as a function of the combination of moisture content and true density. Nalbandi et al. (2010) reported a polynomial relationship for the terminal velocity of wheat kernels as a function of moisture content. The following equations were found for the relationship between the terminal velocity $\left(V_{t}, \mathrm{~m} \mathrm{~s}^{-1}\right)$ and moisture content $(M, \%)$, for:

- Makhobeli:

$$
V_{t}=0.001 M^{2}+0.014 M+4.572 \quad \mathrm{R}^{2}=0.996,
$$

- triticale:

$$
V_{t}=0.053 M+4.981 \mathrm{R}^{2}=0.993,
$$

- wheat:

$$
V_{t}=0.087 M+5.642 \quad \mathrm{R}^{2}=0.992 .
$$

All the indexes are significant at the level of $99.99 \%$.

The values of the drag coefficient and the projected area of Makhobeli, triticale and wheat seeds were calculated using Eqs (2) and (3) by measuring the terminal velocity, true density and the two principal dimensions (length and width) of seeds (Table 1). The analysis of variance showed that there was a significant difference between the drag coefficients of Makhobeli, triticale and wheat seeds at $5 \%$ probability level $(\mathrm{p}<0.05)$. In addition, the effect of seed moisture content on this property was significant at $1 \%$ probability level (Table 2). Meanwhile, the interaction effects of seed crop $\times$ moisture content were not significant for the drag coefficient of seeds ( $p>0.05$ ).

Figure 2 shows the variation of the drag coefficient with moisture content for three crop seeds. The results showed that the drag coefficient of Makhobeli, triticale and wheat seeds decreased as moisture content increased. Afonso et al. (2007), Gupta et al. (2007) and Irtwange and Ugbeka (2003) reported similar results for coffee cherries, sunflower seed and African yam bean ( $c v$. TSS 138), respectively. However, some odd results have been reported for some products. Irtwange and Ugbeka (2003) reported that the drag coefficient of African yam bean ( $c v$. TSS 137) increased as moisture content increased from 4 to $16 \%$ w.b. Afonso et al. (2007) showed that the drag coefficient of coffee beans (cv Catual), coffee cherries and beans ( $c v$. Conilon) increased as moisture content increased.

The drag coefficient values of Makhobeli seeds were found to be $1.60,1.38,1.10,0.85$ and 0.68 with a mean value of 1.12 and standard deviation of 0.43 (Table 3), for the moisture contents of 7, 12, 17, 22 and 27\%, respectively. For triticale seeds, the drag coefficients were found to be 1.18 , $1.02,0.93,0.79$ and 0.68 with a mean value of 0.92 and standard deviation of 0.21 , over the same moisture contents. In addition, the calculated drag coefficients for wheat seeds 


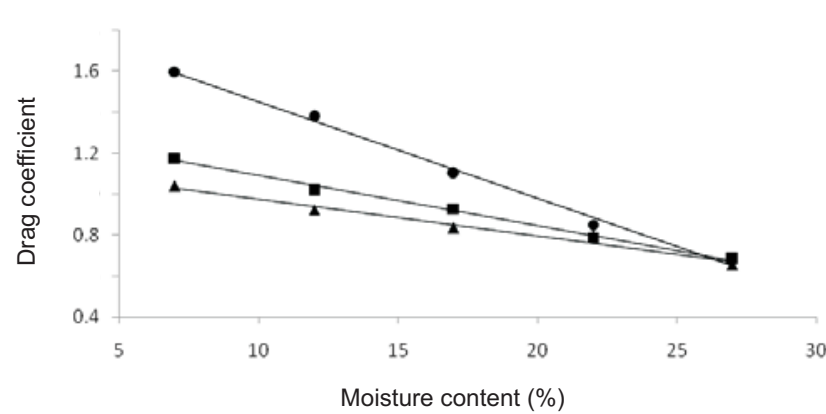

Fig. 2. Drag coefficient variation $v s$. seed moisture content. Explanation as in Fig. 1.

were $1.09,0.92,0.83,0.79$ and 0.65 , with a mean value of 0.85 and standard deviation of 0.44 , over the same moisture contents. The differences between the mean values of the drag coefficients for Makhobeli, triticale and wheat seeds were significant at 5\% level (Table 3). Hauhouot et al. (2000) reported that the drag coefficient of wheat seeds is 0.74. Matouk et al. (2008) reported that the drag coefficient of sunflower, soybean, and canola seeds decreased from 0.75 to 0.61 , from 0.68 to 0.68 and from 0.63 to 0.57 , with the increasing of seeds moisture contents from 7.35 to 23.7 , 9.52 to 24.64 and 7.11 to $25.722 \%$, respectively.

The models fitted to the drag coefficient variation vs. seed moisture content data in Fig. 2, using the regression technique, showed that the drag coefficient decreased linearly with increases in the moisture content for three crops of Makhobeli, triticale and wheat. Similar results were also reported by Matouk et al. (2005) for rice, corn, wheat and barley. They found that the relationship between terminal velocity and moisture content may be described by an exponential model while drag coefficient has a linear relationship. So the following equations were found for the relationship between drag coefficient $\left(C_{d}\right)$ and moisture content $(M, \%)$, for each crop seeds:

- Makhobeli:

$$
C_{d}=-0.047 M+1.925 \mathrm{R}^{2}=0.994,
$$

- triticale:

$$
C_{d}=-0.024 M+1.334 \mathrm{R}^{2}=0.995,
$$

- wheat:

$$
C_{d}=-0.017 M+1.154 \mathrm{R}^{2}=0.979 .
$$

All the indexes are significant at the level of $99.99 \%$.

\section{CONCLUSIONS}

1. The terminal velocity values of triticale and wheat seeds were significantly higher $(p<0.01)$ than those of Makhobeli seeds and the difference between the mean terminal velocity of Makhobeli seeds and mean terminal velocities of triticale and wheat seeds were about 1.16 and $2.40 \mathrm{~m} \mathrm{~s}^{-1}$, respectively. Consequently, aerodynamic separation of Makhobeli from triticale and wheat is theoretically possible if the air velocity value is adjusted according to the terminal velocity of Makhobeli seeds.

2. Terminal velocity of triticale and wheat seeds increased linearly from 5.37 to 6.42 and 6.31 to $8.02 \mathrm{~m} \mathrm{~s}^{-1}$, respectively, as the moisture content increased from 7 to $27 \%$. Over the same moisture content range, the terminal velocity of Makhobeli seeds varied following a polynomial relationship from 4.52 to $5.07 \mathrm{~m} \mathrm{~s}^{-1}$.

3. There was a significant difference between the drag coefficients of Makhobeli, triticale and wheat seeds at 5\% probability level $(p<0.05)$. In addition, the effect of seed moisture content on this property was significant at $1 \%$ probability level. The drag coefficient of all seed crops decreased linearly with the increase of moisture content.

\section{REFERENCES}

Afonso Jr. P.C., Correa P.C., Pinto F.A.C., and Queiroz D.M., 2007. Aerodynamic properties of coffee cherries and beans. Biosys. Eng., 98, 39-46.

Arora S., 1991. Physical and aerodynamic properties of rough rice (Oryza sative). Indian J. Agric. Eng., 1(1), 17-22.

ASAE, 1998. ASAE Standards. St. Joseph, MI, USA.

Baryeh E.A., 2002. Physical properties of millet. J. Food Eng., 51, 39-46.

Chakraverty A. and Paul S.R., 2001. Post Harvest Technology: Cereals, Pulses and Vegetables. Sci. Publ., India.

Gupta R.K., Arora G., and Sharma R., 2007. Aerodynamic properties of sunflower seed (Helianthus annuus L.). J. Food Eng., 79, 899-904.

Hauhouot O.M., Criner B.R., Brusewitz G.H., and Solie J.B., 2000. Selected physical characteristics and aerodynamic properties of cheat seed for the separation from wheat. Agric. Eng. Int., 2, 1-14.

Irtwange S.V. and Ugbeka J.C., 2003. Effect of accession and moisture content on aerodynamic properties of African yam bean (Sphenostylis stenocarpa). Appl. Eng. Agric., 19(3), 321-328

Jha S.N. and Kachru R.P., 2007. Physical and aerodynamic properties of makhana. J. Food Proces. Eng., 21, 301-316.

Karaoglu M.M., 2006. Cephalaria syriaca addition to wheat flour dough and effect of on rheological properties. Int. J. Food Sci. Technol., 41, 37-46.

Khoshtaghaza M.H. and Mehdizadeh R., 2006. Aerodynamic properties of wheat kernel and straw materials. Agric. Eng. Int., CIGR Ejournal, 8, 1-10.

Matouk A.M., Abd El-latif S.M., and Tharwat A., 2008. Aerodynamic and mechanical properties of some oil crops. J. Agric. Sci. Mansoura Univ., 33(6), 4195-4211.

Matouk A.M., El-Kholy M.M., Hamam A.S., and Ewis T.R., 2005. Aerodynamic characteristics for different varieties of some cereal crops. J. Agric. Eng. Res., 22(3), 1086-1102.

Mohsenin N.N., 1978. Physical properties of plant and animal materials. Gordon Breach Sci. Press, New York, USA. 
Musselman L.J., 2000. Zawan and tares in the Bible. Economic Botany, 54, 537-542.

Nalbandi H., Seiiedlou S., and Ghassemzadeh H.R., 2010. Aerodynamic properties of Turgenia latifolia seeds and wheat kernels. Int. Agrophys., 24, 57-61.

Ozguven F. and Vursavus K., 2005. Some physical, mechanical and aerodynamic properties of pine (Pinus pinea) nuts. J. Food Eng., 68, 191-196.

Razavi S.M.A., Rafe A., and Akbari R., 2007. Terminal velocity of pistachio nut and its kernel as affected by moisture content and variety. African J. Agric. Res., 2(12), 663-666.
Shahbazi F., 2013. Aerodynamic properties of wild mustard (Sinapis arvensis L.) seed for separation from canola. J. Sci. Food Agric., 93, 1466-1470.

Tabak S. and Wolf D., 1998. Aerodynamic properties of cottonseeds. J. Agric. Eng. Res., 70, 257-265.

Unal H., Alpsoy H.C., and Ayhan A., 2013. Effect of the moisture content on the physical properties of bitter gourd seed. Int. Agrophys., 27, 455-461.

Zare D., Bakhshipour A., and Chen G., 2013. Physical properties of cumin and caraway seeds. Int. Agrophys., 27, 491-494.

Zewdu A.D., 2007. Aerodynamic properties of tef grain and straw material. Biosys. Eng., 98, 304-309. 